\title{
Nursing Practice on Post-Operative Wound Care in Surgical Wards at Muhimbili National Hospital, Dar-es-Salaam, Tanzania
}

\author{
Adela A. Mwakanyamale ${ }^{1 *}$, Anna Mary A. Mukaja1, Mathew D. Ndomondo ${ }^{1}$, Joan P. Zenas ${ }^{2}$, \\ Ambroce M. Stephen², Elizabeth Z. Mika² \\ ${ }^{1}$ Department of Medical and Surgical Nursing, Faculty of Nursing, Hubert Kairuki Memorial University, Dar-es-Salaam, \\ Tanzania \\ ${ }^{2}$ Department of Fundamentals of Nursing and Basic Sciences, Hubert Kairuki Memorial University, Dar-es-Salaam, Tanzania \\ Email: ‘ademwaka@yahoo.com, mukaja3anna@gmail.com, Mathew.ndomondo@bn.hkmu.ac.tz, joanzenas@gmail.com, \\ ambroceste2012@gmail.com,mikaelizabeth@yahoo.com
}

How to cite this paper: Mwakanyamale, A.A., Mukaja, A.M.A., Ndomondo, M.D., Zenas, J.P., Stephen, A.M. and Mika, E.Z. (2019) Nursing Practice on Post-Operative Wound Care in Surgical Wards at Muhimbili National Hospital, Dar-es-Salaam, Tanzania. Open Journal of Nursing, 9, 870-890. https://doi.org/10.4236/ojn.2019.98065

Received: July 15, 2019

Accepted: August 19, 2019

Published: August 22, 2019

Copyright $\odot 2019$ by author(s) and Scientific Research Publishing Inc. This work is licensed under the Creative Commons Attribution International License (CC BY 4.0).

http://creativecommons.org/licenses/by/4.0/ c) (i) Open Access

\begin{abstract}
Background: Postoperative wound healing has been a problem which causes high mortality in the developing world; postoperative wound has been reported to cause devastating consequences and a measurable mortality. There is a limited number of published studies in Tanzania investigating Nursing practice on post-operative wound care in surgical wards at Muhimbili National Hospital, Dar-es-Salaam, Tanzania. This study assesses nursing practice on postoperative wound care by nurses in surgical wards at Muhimbili National Hospital. Methods: A cross-sectional study of surgical nurses was carried out through the use of randomly selected surgical wards at Muhimbili National Hospital in Tanzania from September 2011 to July 2013. A multistage cluster sampling technique was used to obtain a suitable number of study participants. Data collection was done using a checklist from a convenient sample of 71 nurses in selected surgical wards. Results: The result indicates that a big number of the participants were female (76.5\%) and those of the age group 25 to 34 years were $40.8 \%$. Participants exceeding a half of the selected sample reported to have poor post-operative wound care practice (57.7\%). In comparison, male participants scored higher, and had better practice than their female counterparts, however, there was no considerable difference in the scores $(\mathrm{P}=0.803)$. During set-up and preparation phase, the washing of hands before starting and after the completion of procedure was taken into consideration by less than half of the participants (49.3\%). All participants did not ensure the environment is clean and take into account the patient's privacy through the use of screen or even closing the room. The report shows that nurses take into consideration putting on clean gloves dur-
\end{abstract}


ing the removal of the old dressing (99\%), the use of sterile gloves during wound dressing was taken into consideration by most of the nurses (63\%). Good practice was noted in applying dressing solution as recommended (85\%), dry sterile dressing was applied by $(90 \%)$, arrangement and setting up of dressing forceps and other items that may be needed in order of their application using forceps (20\%), usage of forceps to dip gauze into antiseptic solution (35\%) and cleaning of the wound cleaning from least contaminated to most contaminated area was only adhered to by (34\%). Post-operative counseling and giving to the patient not to temper with the wound was done by a representation of only $15 \%$ of nurses. All the nurses did not do the documentation of the changes observed on the wound nor did they report on the patients comfort and the date and time after the procedure wound changes, reported patient comfort, and recorded date or time after the procedure. Conclusion: Majority of the nurses in surgical wards do not follow the postoperative wound care checklist provided by $\mathrm{MNH}$ although they know its importance. Assessment of the wound and documentation continues to be a problem in the nursing profession in Tanzania. Nurses are reasonably knowledgeable about the principal of wound dressing; however, lack of knowledge on some of the key principles of wound dressing is worth noting. Almost half of the nurses do not wash hands before and after the procedures, they don't use single gauze in one direction only, not cleaning from least contaminated to most contaminated area, which can lead to wound contamination.

\section{Keywords}

Wound, Post-Operative Care, Wound Dressing, Infection

\section{Background}

Postoperative wound infection has been a problem which causes high mortality in the developing world [1]. Postoperative wounds have been reported to cause devastating consequences and measurable mortality [2]. Regardless of the advancement in the operative techniques and improved understanding of the pathogenesis of wound infection, postoperative wound infection has continued to be a major source of morbidity and mortality especially for the patients undergoing operative procedures [3]. The rates of wound healing have been reported to vary in different countries, in different areas and even in different hospitals [4]. A recent study in Nigeria shows that $70-80$ percent of both morbidity and mortality are due to wound infections [5].

According to Nasser et al. (2003) [6], wound healing has been associated with many factors, the common factors are: malnutrition, age, surgical site infections (SSIs), presence of infective foci, diabetes, hygienic conditions and duration of operation. Woo et al. (2015) [7] report that SSIs have led to a high proportion of healthcare-associated infections (HCAIs) accounting to 20 percent of all HCAIs, 
and affect more than 5 percent of patients who had surgery. Additionally, wound dressing practice has been also mentioned to be among the factors which affect wound healing. Wound dressing practice using gauze is disruptive to the healing wound as it dries and causes tissue damages when it is removed. Inappropriate use of dressing may lead to unwanted effects [7]. Gove et al. (2014) [8] claim that the management of postoperative wounds has perhaps been given less attention than it is required, with more emphasis being on the nursing care of chronic wounds.

Gove et al. (2014) [8] report that a range of guidance and recommendations regarding postoperative dressing practice have been provided to health care workers in the United Kingdom (UK).

Dowsett et al. (2015) [9] recommended that at the end of the operation surgical incisions thought to heal through primary intention need to be covered by a film membrane with or without a central absorbent. Currently, postoperative dressing practice comprises of the use of a vapor-permeable film dressing as those suggested by Dowsett et al. (2015) [9]. Although there has been an advancement in the operative techniques, methods and improved understanding of the pathogenesis of wound infection, postoperative wound infection continues to be a major source of morbidity and mortality for patients undergoing operative procedures [10].

Post-operative wound infection has been noted to be one of the highest common causes of nosocomial infections which constitute of $20 \%$ to $25 \%$ of all nosocomial infections worldwide [11]. Post-operative wound infections have been one of the factors for increasing cost, morbidity and mortality related to surgical operations and are increasingly becoming a major problem worldwide [12]. Globally, surgical site infection rates have been reported to range from $2.5 \%$ to $41.9 \%$ [13].

In the United States, approximately $2 \%$ to $5 \%$ of the 16 million patients who undergo surgery each year have postoperative surgical site infections [14].

Despite improvements in operating room techniques and methods, instrument sterilization methods, improved surgical techniques and the more efforts on infection prevention mechanism, surgical site infections remain a major cause of hospital-acquired infections and rates are increasing worldwide even in hospitals with most advanced facilities and standard protocols of preoperative preparation and antibiotic prophylaxis [15].

Surgical site infections are the most experienced hospital attained infection occurring in the early stage of postoperative period in surgical patients. It can be linked with morbidity, mortality and increased resource utilization.

Surgical site infections account for $38 \%$ of all infections in surgical patients and $31.1 \%$ of all infections in trauma patients [16].

Despite advances in the operative techniques and improved knowledge of the pathogenesis of wound infection, postoperative wound infection is increasingly becoming a major source of morbidity and mortality for patients undergoing operative procedures [17]. 
Regardless of the advancement made in technology related to surgery and wound management, wound infection has been regarded as the most common nosocomial infection especially in the patients undergoing surgery [18], it is a common known cause of illness that results in prolonged staying in the hospital, costs increase and more resource-demanding for general wound management practices [19]. SSI continues to remain a major problem in hospitals, contributing considerably to increase rate of morbidity, mortality and cost of care [20]. The problem is even more chronic and serious in developing countries where resources are limited and with staff supply being low [21].

Previously a study conducted in one of the districts and a tertiary hospital in Tanzania indicated surgical site infections rate of $19.4 \%$ and $24 \%$ respectively [22].

In Tanzania, postoperative wound healing still remains a problem to surgical patients and a challenge to clinicians despite that much effort on wound care management has been provided. Tanzania still suffers from a lack of qualified health workers. Increased burden of diseases affects the quality and supply of effective health services, which has seen postoperative patients get inadequate wound treatment and wound (dressing) care management in surgical wards, resulting to wound healing delay and complications [23]. This study sought to assess the nursing practice used by nurses to care for the postoperative wound in surgical wards at Muhimbili National Hospital Tanzania.

\section{Methods}

\subsection{Study Design}

A cross-sectional study of surgical nurses was carried out through the use of randomly selected surgical wards at Muhimbili National Hospital in Tanzania from September 2011 to July 2013.

A multistage cluster sampling technique was also used to obtain the required number of study participants.

\subsection{Participants}

The target population comprised male and female surgical nurses (registered and enrolled) working in surgical wards at $\mathrm{MNH}$, aged 18 - 60 years. A total of 71 nurses were recruited (53 registered nurse 18 enrolled nurses).

\subsection{Data Collection-Instruments}

Data were collected (gathered) by the use of checklist on standard nursing practice on wound care (see Appendix 1). The tool is a pre-designed one from $\mathrm{MNH}$ and also it follows the standard's principles of wound dressing and it is internationally acceptable. The content of Validity of the checklist was assessed by the panel of experts from a Quality control unit of $\mathrm{MNH}$.

The first part of the checklist included questions pertaining to demographic data: For example, age, education, and gender. The second part of the tool was 
on standard nursing practice on wound care, the third part of the tool included questions on availability of dressing materials, the fourth part of the tool included assessment on the proper use of available dressing materials, the tool was in English language.

The assessment was done during the working days of the week (Monday to Friday). A duty roster was used to avoid double observation of the study participants. In this study, the data was collected from the participants who met inclusion criteria of the study after seeking their consent.

\subsection{Sampling Technique}

Sampling was done by the researcher herself. The study participants were obtained on convenient basis from those eligible nurses who were on duty during the data collection period.

The calculated estimated sample size for the study was 165 but due to small number of registered and enrolled nurses in surgical wards compared to calculated sample size, all nurses in surgical wards at the time of study who gave consent formed the sample size. This is due to a number of reasons as some of nurses being in Annual leave and some in school leave, so 71 nurses gave the consent and participated in the study.

We employed multistage cluster sampling technique. First, we randomly selected five surgical wards; second, we used simple random sampling in selecting three wards and from each ward, 71 nurses were randomly selected through simple random sampling.

\subsection{Statistical Analysis}

The Statistical Package for Social Sciences software (SPSS for windows 15.0, SPSS Inc., Chicago, IL, USA) was used in computing statistical analyses.

Descriptive analysis was done and used to present results in frequency distributions tables and bar graphs. Mean was calculated in determining nurses postoperative wound care scores with the difference in mean scores used as a measure for poor and better post-operative wound care practice. Independent sample $\mathrm{t}$-test was done and used in assessing the significant difference in mean practice score with a $p$-value of 0.05 considered as a significance level at $95 \%$ confidence interval with ANOVA done for multiple comparisons. Chi-square test was used to assess the association between nurses' proper use of available dressing material with a $p$-value of 0.05 considered significant at $95 \%$ confidence interval.

\section{Results}

\subsection{Description of the Sample}

As shown in Table 1, a total of 71 nurses participated in this study. Of those 55 (76.5\%) were female and $16(22.5 \%)$ were male. $40.8 \%$ of nurses were of age group between 18 to 60 years. Only two (2.8\%) participants were less than 24 years old. Enrolled nurses were 18 (25.4\%). Nearly three quarter 53 (74.6\%) were registered nurses. 
Table 1. Distribution of participant by demographic characteristics.

\begin{tabular}{cccc}
\hline Factors & Specific variable & Number $\mathbf{N}=\mathbf{7 1}$ & Percentage \\
\hline \multirow{2}{*}{ Sex } & Male & 16 & 22.5 \\
& Female & 55 & 76.5 \\
\hline \multirow{2}{*}{ Age (year) } & Less than 24 & 2 & 2.8 \\
& 25 to 34 & 29 & 40.8 \\
& 35 to 44 & 26 & 36.6 \\
& More than 45 & 14 & 19.7 \\
Professional Education level & Certificate & 18 & 25.4 \\
& Diploma & 43 & 60.6 \\
& Degree & 10 & 14.1 \\
\hline \multirow{2}{*}{ Job title } & Registered Nurse & 53 & 74.6 \\
& Enrolled Nurse & 18 & 25.4 \\
\hline
\end{tabular}

\subsection{Nurse's Practice towards Post-Operative Wound Care}

All items involving nurses' practice on wound care were assessed. A correct practice was scored 1 and incorrect or undone procedure was scored 0 . Total scores for overall practice and the scores were compared on socio-demographic characteristics. The mean score of nurses' practice was 16.42 .

Score below the mean was considered as a poor postoperative wound care and a score above was considered as a good practice. Table 2 below summarizes the results on practice scores with the socio-demographic characteristics.

In general, 30 participants (42.3\%) were observed to have good post-operation wound care or wound care management and more than half of participants (57.7\%) had poor operation wound care practice. Male participants scored higher score on post-operative wound care compared to their female counterparts, however, there was no considerable difference between scores $(\mathrm{P}=0.803)$.

Low post-operative wound care score was recorded for participants aged 34 years and below. Nurses with 15 to 24 years and 25 to 34 years had 14.5 and 16.38 scores respectively. Higher scores were observed in participants aged d 35 to 44 years $(16.65 \%)$. No significant difference was observed in practice scores between participants of different age group $(\mathrm{P}=0.844)$.

Undergraduate nurses had good practiced and scored higher compared to others. There was unsatisfactory post-operative wound care in nurses with diploma and poor practice in nurses with certificate level of education. There was a considerably better practice between undergraduate nurses compared to diploma trained nurses $(\mathrm{P}=0.003)$. Moreover, good post-operative wound practice was observed among undergraduate nurses compared to certificate holding nurses $(\mathrm{P}=0.006)$.

However, no significant difference in score between nurses having certificate training and those with diploma level of education $(\mathrm{P}=0.907)$. Registered nurses 
Table 2. Practice scores with socio-demographic characteristics.

\begin{tabular}{cccc}
\hline Variable & Category & Mean & $\pm p$-Value \\
\hline Sex & Male & 16.62 & $\mathbf{0 . 8 0 3}$ \\
& Female & 16.36 & \\
Age (year) & 18 to 24 & 14.5 & $\mathbf{0 . 8 4 4}$ \\
& 25 to 34 & 16.38 & \\
& 35 to 44 & 16.65 & $\mathbf{0 . 0 0 6}$ \\
Professional & $45+$ & 16.36 & $\mathbf{0 . 9 0 7} \boldsymbol{f}$ \\
Education level & Certificate & 15.67 & $\mathbf{0 . 0 0 5 g}$ \\
& Diploma & 16.02 & $\mathbf{0 . 2 5 4}$ \\
\hline Job title & Degree & 19.5 & \\
\hline
\end{tabular}

${ }^{*} P$-Value for score between nurses with Certificate and degree; $\int p$-Value for score between nurses with Certificate and Diploma; $\boldsymbol{g} p$-Value for score between nurses with Diploma and degree; \pm (Independent sample t-test in comparing mean between sex and Job title, ANOVA was used in comparing mean difference between age groups and professional education level).

scored higher compared to enrolled nurses. There was no significant difference in scores between enrolled nurse and enrolled nurses $(\mathrm{P}=0.254)$.

\subsection{Assessment of Nurses on Post-Operative Wound Care Procedure-Preparation Phase}

As shown in Figure 1 below, assessing the preparation phase for post-operative wound care. All nurses were able to make sure that the waste bag was within reach. $81.7 \%$ of respondents were able to discuss with the patient about the procedure. Assembling of all needed supplies was done by $64.8 \%$ of nurses. Nearly half of the nurses observed hand washing before and after procedure. $49.3 \%$ of nurses assisted the patient to assume the comfortable position All the nurses did not there is clean and safe surrounding environment ahead of starting the procedure. The privacy of patients was not observed since none of the nurses closed nor screened the room before starting the procedure.

\subsection{Distribution of Nurse's Practice on Post-Operative Wound Care-Usage of Dressing Equipment}

As shown in Figure 2 below, the use of clean gloves by the nurses was observed, with $99 \%$ using them effectively. All nurses were able to remove old dressing leaving inner dressing, $99 \%$ used normal saline to soak and remove stuck dressing from the wound. $97 \%$ of the nurses disposed inner dressing and put them in the waste bag, $68 \%$ removed disposable groves and $63 \%$ put on a sterile glove. Usage of forceps in lifting inner dressing was observed by only half of respon- 
dents (52\%) and less than half of nurses (48\%) took time to observe the nature of the wound during dressing.

\subsection{Distribution of Nurses' Practice on Post-Operative Wound Care-Dressing Phase}

In Figure 3 below, there was an observation of good practice during application of dressing solution as in the directives by $85 \%, 87 \%$ poured antiseptic solution into the sterile receiver, $90 \%$ applied dry sterile dressing, and all nurses used tape as adhesive plaster or bandage. Less than $40 \%$ of the nurses prepared the forceps to be used for dressing and all other required items in order to their application using forceps, $32 \%$ made use of the forceps for dipping the gauze into antiseptic solution and $34 \%$ observed cleaning of the wound from least contaminated to most contaminated area.

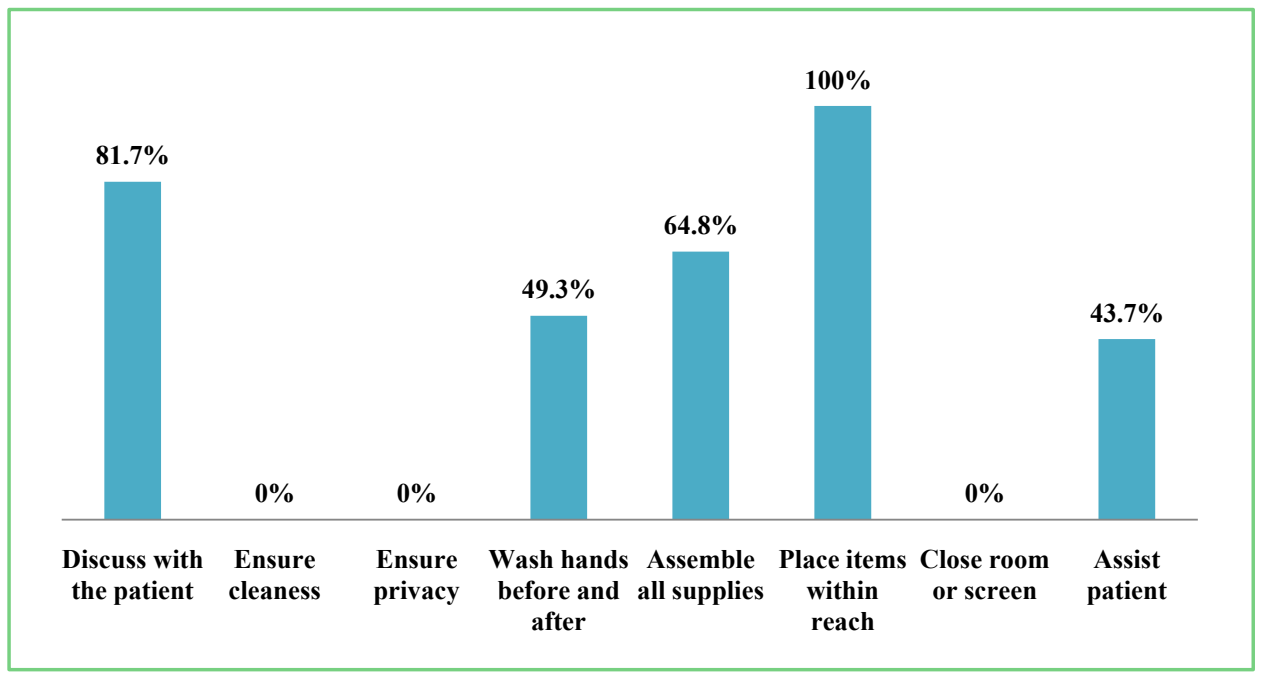

Figure 1. Assessment of nurses on post-operative wound care procedure in percentage.

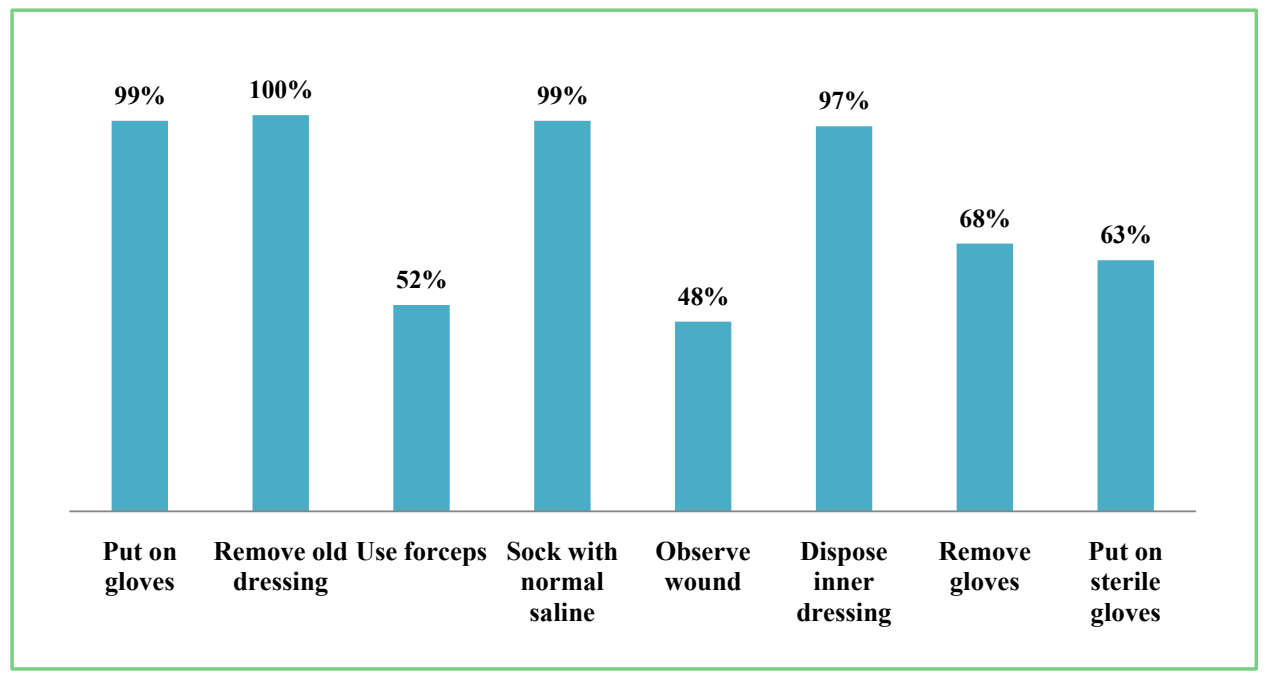

Figure 2. Distribution of nurse's practice on post-operative wound care-usage of dressing equipment. 


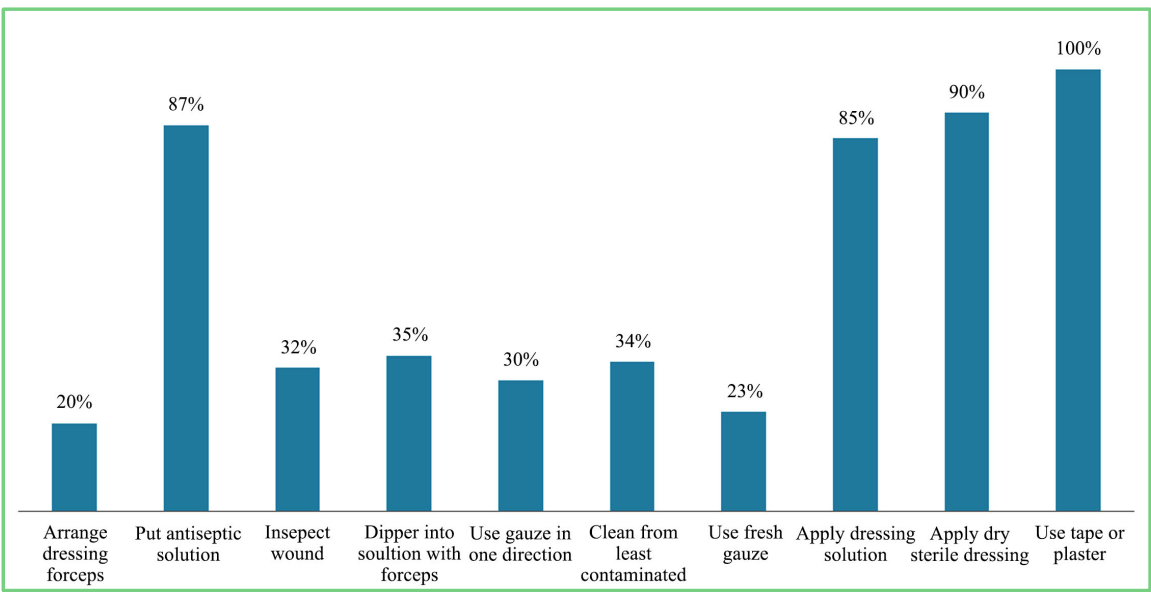

Figure 3. Distribution of nurses' practice on post-operative wound care-dressing phase.

\subsection{Nursing Practice on Post-Operative Wound Care-Counseling and Documentation}

As shown in Figure 4, all nurses cleaned all used equipment. Post-operative counseling and giving instructions to the patient not to temper with the wound was done by only $15 \%$ of nurses and only $10 \%$ of nurses recorded wound changes. All the nurses did not document changes of the wound, reported patient comfort, neither recorded date nor time after the procedure.

\subsection{Availability of Dressing Equipment}

Table 3 below shows there was a good availability of items in the dressing pack. Non toothed forceps was available by $62 \%$ while $70.4 \%$ dressing towel was available in cases assessed.

Moreover, Artery forceps was not available at all in all assessed cases. In terms of dressing solutions, Normal saline, spirit and povidone were available through hydrogen peroxide and eusol Solution was not available at all.

In general, enough dressing equipment was available although there were inadequate masks, Plastic Apron, Jar cheatle, cheatle forceps and dressing mackintosh. There were adequate clean and sterile gloves, drums, trolleys and containers for dirty items.

\subsection{Assessment of Nurses on Proper Usage of Available Dressing Material}

Table 4 below shows that registered nurses demonstrated better usage of dressing material than enrolled nurses. Almost all nurses placed the waste bag for soiled items within reach, dusted trolley for carrying equipment, usage on dressing solutions, usage of forceps in wound dressing and usage of fresh gauze to dry the wound. However enrolled nurses performed better than registered ones in the usage of gloves, and gauze in one direction. There was no statistically significant difference in the usage of dressing materials between registered and enrolled nurses in all procedures $(\mathrm{P}>0.05)$. 


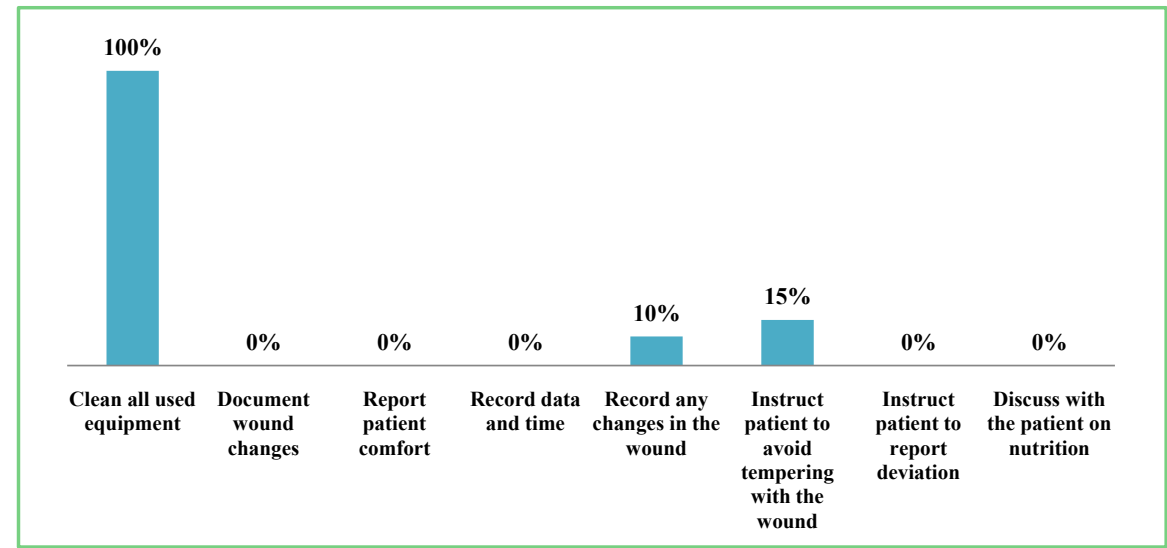

Figure 4. Nursing practice on post-operative wound care-counseling and documentation.

Table 3. Distribution of availability of dressing equipment.

\begin{tabular}{|c|c|c|}
\hline Item & Present (\%) & Not present (\%) \\
\hline \multicolumn{3}{|l|}{ DRESSING PACK } \\
\hline Toothed dissecting Forceps & $71(100)$ & - \\
\hline Non toothed dissecting forceps & $44(62)$ & $27(38)$ \\
\hline Dressing Towel & $50(70.4)$ & $21(29.6)$ \\
\hline Gauze & $69(97.2)$ & $2(2.8)$ \\
\hline Cotton Swab & $68995.8)$ & $3(4.2)$ \\
\hline Gall Pot & $70(98.6)$ & $1(1.4)$ \\
\hline Kidney Dish & $69(97.2)$ & $2(2.8)$ \\
\hline Artery Forceps & - & $71(100)$ \\
\hline \multicolumn{3}{|l|}{ DRESSING SOLUTION } \\
\hline Normal Saline & $71(100)$ & - \\
\hline Spirit & $71(100)$ & - \\
\hline Eusol Solution & - & $71(100)$ \\
\hline Hydrogen Peroxide & - & $71(100)$ \\
\hline Povidone & $71(100)$ & - \\
\hline \multicolumn{3}{|l|}{ DRESSING EQUIPMENTS } \\
\hline Trolley & $60(84.5)$ & $11(15.5)$ \\
\hline Mask & - & $71(100)$ \\
\hline Drum & $71(100)$ & - \\
\hline Plastic Apron & - & $71(100)$ \\
\hline Sterile Gloves & $60(84.5)$ & $11(15.5)$ \\
\hline Bandage & $67(94.4)$ & $4(5.6)$ \\
\hline Container for Soiled Items & $71(100)$ & - \\
\hline Cheatle Forceps & - & $71(100)$ \\
\hline Jar Cheatle & - & $71(100)$ \\
\hline Dressing Macintosh & $10(14.1)$ & $61(85.9)$ \\
\hline Clean Gloves & $71(100)$ & - \\
\hline
\end{tabular}


Table 4. Distribution of nurses on proper usage of available dressing materials (Chi-square test to assess association on proper usage between registered and enrolled nurses).

\begin{tabular}{|c|c|c|c|}
\hline Dressing material & $\begin{array}{l}\text { Registered } \\
\text { Nurses }\end{array}$ & $\begin{array}{l}\text { Enrolled } \\
\text { Nurses }\end{array}$ & p-Value \\
\hline & $\mathrm{N}(\%)$ & $\mathrm{N}(\%)$ & \\
\hline Dust dressing Trolley for carrying equipment & $37(69.8)$ & $8(44.4)$ & 0.054 \\
\hline Place waste bag for soiled item within reach & $48(90.6)$ & $13(72.3)$ & 0.053 \\
\hline Put on disposable (clean) gloves when open wound & $39(73.6)$ & $15(83.3)$ & 0.402 \\
\hline $\begin{array}{l}\text { Using toothed dissecting forceps to lift inner dressing off } \\
\text { slowly }\end{array}$ & $40(75.5)$ & $11(61.1)$ & 0.242 \\
\hline $\begin{array}{l}\text { Use normal saline to sock the wound if dressing stick on the } \\
\text { wound }\end{array}$ & $47(88.7)$ & $17(94.4)$ & 0.478 \\
\hline $\begin{array}{l}\text { Pour antiseptic solution into sterile receiver (kidney dish or } \\
\text { gall pots) }\end{array}$ & $41(77.4)$ & $11(61.1)$ & 0.027 \\
\hline $\begin{array}{l}\text { Put on sterile gloves while dressing the wound } \\
\text { (Use one glove for one patient) }\end{array}$ & $29(54.7)$ & $9(50)$ & 0.62 \\
\hline $\begin{array}{l}\text { Clean the wound by using forceps } \\
\text { (non-toothed dissecting forceps) }\end{array}$ & $18(34)$ & $4(22.2)$ & 0.414 \\
\hline Use single sterile gauze in one direction only & $12(22.6)$ & $8(44.4)$ & 0.167 \\
\hline Use fresh gauze to dry the wound & $28(52.8)$ & $5(27.8)$ & 0.061 \\
\hline Apply dressing solution as prescribed & $60(84.5)$ & $11(15.5)$ & 0.262 \\
\hline Apply dry sterile dressing & $53(74.6)$ & $18(25.3)$ & - \\
\hline
\end{tabular}

\section{Discussion of Results}

A total of 71 nurses were included in this study. Of those three quarters were female. This high percent of females in the study can be explained by the dominance of nursing profession in Tanzania. Majority of respondents (40.8\%) were of age group between 25 to 34 years. Less than $3 \%$ of nurses had less than 24 years. Sixty percent of nurses had diploma level of education. This can be explained by few enrollments of nurses in degree programs. This study also demonstrates that nearly seventy percent of nurses were registered and this could be due to the diploma level of education, and the fact that $\mathrm{MNH}$ is a referral hospital.

In general, only $42.3 \%$ of nurses had good practice on post-operative wound care with more than half demonstrating bad post-operative wound practice. This is contrary to studies done by [24] colleagues that demonstrate accepted level of good post-operative wound care. Poor post-operative wound care can be to insufficient education and training on wound care and inadequate number of nurses who does not meet demand. This could also be because of failure to adhere to the wound dressing checklist issued by the MNH. Similar results have been documented in the study that was done by [25].

Female nurse did not record better performance on postoperative wound care compared to the male ones however, there was no statistically significant differ- 
ence. Postoperative wound care observed on the young nurses was poor compared to older ones with no statistical significant difference. This is a result of lack of experience in nursing care and the fact that most of them had having low levels of professional education. Some studies done by Greatrex-White et al. (2013) [24] established that old nurses had good post-operative wound care in comparison to young of which it is reflected by an increase in percentage of good practice with an increase in age.

The same results demonstrated that aged nurses possess good practice owed to their experience in wound management in this case participants with three years of experience and above had better practice compared to less experienced ones [26]. And the same results are demonstrated by Christine [27] that showed better practice in aged nurses. Undergraduate nurses scored higher with evidence of good practice compared to those with diploma (registered nurses) and enrolled or certificate level of education, however no significant difference in practice among nurses with certificate and diploma level of education. Good post-operative wound care practice among the undergraduate nurses could be as a result of education and training acquired or due to the fact that they are experienced. Similarly, a number of studies have highlighted on the role of education and training in promoting and improving better post-operative wound care [28].

Registered nurses recorded a higher performance with good postoperative wound care compared to enroll nurses though it did not demonstrate notable statistical significant difference. This could be related to high level of education they possess and good practice in post-operative wound care. With emphasis, complete holistic approach should be performed to highlight the etiology of the wound and factors that contribute to healing as insisted by [29].

This study validates that privacy was not observed while attending patients as none of the nurses screened before doing the procedure. This could be as a result of inadequate screens to provide for the needs and requirements of all patients, unfavorable environment for procedures as the wards were overcrowded. The same findings have been demonstrated by the study done by Mahoney and Kirsty [30] that showed the problem of overcrowding brings difficulties in ensuring and maintaining privacy for patients. There is also poor practice that could result in contamination that was observed as no nurse observed a clean and safe environment before the procedure with only a half of them washing their hands before and after the procedure.

There was an observation of good use of clean gloves which is a good practice for personal protection though $37 \%$ of nurses did not change to sterile gloves on wound dressing. This demonstrates poor practice and could lead to wound infections. Wound dressing being a non-touch technique use of forceps was expected throughout the dressing procedure. Results indicate that only half of nurses make use of forceps in wound dressing. As noted earlier the reason for this could be as a result of lack of adequate education, training and non-adherence to wound dressing checklist. Wound inspection was observed in only half of the nurses. This is contrary to a study done by Mukagendaneza et al. [31] confirmed 
good practice in wound inspection before dressing as noted in $81 \%$ of participants.

Nurses revealed poor wound dressing techniques. With only $30 \%$ of nurses using single gauze in one direction. This is a source of wound infection. Moreover, only $23 \%$ of nurses ensured the use of clean gloves whenever cleaning the wound and only $35 \%$ of nurses cleaned the wound from the less contaminated area to the most contaminated one. These findings proved poor wound dressing practice. Poor documentation of after wound assessment and dressing is also another evidence demonstrated in this study as all the nurses did not document the date and time after wound assessment. Only $15 \%$ of nurses were keen to instruct the patients not to temper with the wound after the dressing.

The number of patients was bigger than the available dressing packs thus not matching the need. A good number of toothed forceps was available together with Cotton swab, Gauze, and kidney dish. On the other hand, dressing towels were accessible to only $70.4 \%$ of nurses. Artery forceps were not available at all.

Eusol solution and hydrogen peroxide solution were not available at all but there was adequate available amount of normal saline and spirit.

A number of dressing equipments were available although there was scarcity of masks, plastic aprons, jar cheatle, cheatle forceps and dressing mackintosh. There were a good number of clean and sterile gloves, Drum Trolleys and Containers for soiled items. Unavailability of dressing material could be attributed to low economic power of the MNH Hospital to purchase their items. These findings are different from the study [32] that demonstrated a better usage of dressing materials.

Registered nurses proved better usage of the materials for dressing compared to their enrolled counterpart. This could be attributed to good education attained and experience in wound dressing. The same results on influence of education and experience in good usage on dressing materials were shown in studies done by [33]. There was proper use of waste bags for disposing of the items already soiled within reach, trolley adequately dusted for equipment carrying, dressing solutions usage, forceps using during wound dressing and the use of fresh gauze for drying the wound. However, registered nurses did not perform well as compared to the enrolled ones during the use of gloves and the use of gauze in one direction. These results could be attributed to the fact that $\mathrm{MNH}$ is the referral hospital so it employs very qualified nurses.

\section{Conclusions}

Majority of the nurses do not follow the postoperative wound care checklist provided, although they know its importance. Assessment of the wound and documentation continues to be a problem in the nursing profession in Tanzania.

Nurses are reasonably knowledgeable about the principal of wound dressing; however, lack of knowledge on some of the key principles of wound dressing is worth noting.

Almost half of the nurses do not observe hygiene before and after the proce- 
dures, they don't use single gauze in one direction only, don't clean wounds from least contaminated to most contaminated area, which can also lead to wound contamination.

\section{Recommendation}

Ministry of Health and Social Welfare should design and implement a continuous professional education programme on post-operative wound care with special focus on how to use the checklist in wound care. To ensure proper and continuous use of the checklist, adequate number of nurses on a particular shift should be ensured, a conductive environment maintained provision of supportive supervision by experienced and skilled nurses and presence of dedicated management team.

It is important that all necessary dressing equipment and solutions should be made available and accessible in order to provide high quality postoperative wound care. Inadequate staffing is a systematic problem that needs to be addressed by leaders at the $\mathrm{MNH}$ and policy makers at the Ministry of Health in Tanzania.

A policy that will enhance capacity building and advancing the skills for nurses during caring for post-operative patients need to be adopted to address issues of periodic nurse training, training of the staff, and putting of research findings into practice and ensuring that the ones trained remain on the units where their performance can be effectively utilized without rotating them to other units. This can be steered by the clinical nurse in charge and leaders in their respective hospitals and the Ministry of Health. Further research is recommended to be undertaken in various contexts similar to and different from this study. Studies are recommended which incorporate larger and more diverse samples of nurses caring for post-operative patients in order to have a wide understanding of this phenomenon.

\section{Limitations of the Study}

This study reports on nurses in surgical wards at $\mathrm{MNH}$, therefore, may not be a true representative of general population.

\section{Ethics Approval and Consent to Participate}

All participants were given information about the study, and they were asked for their voluntary participation. A written informed consent (agreement to participate in the study) was sought and obtained from all nurses before enrolled in the study. Permission to conduct research study was obtained from Muhimbili National Hospital administration, Ethical clearance was obtained from MUHAS Research and Publication Committee before the start of data collection. In this study, the researcher observed the Ethical principles of beneficence, respect of human dignity, fair treatment, self-respect, protection of human rights and honesty in data processing. Confidentiality was granted as the participants were 
identified by number and not by their names to ensure anonymity

\section{Availability of Data and Materials}

The datasets used and analyzed during the current study are available from the one reasonable request.

\section{Authors' Contributions}

AAM conceived the study, participated in study design, literature search, and data analysis and drafted and submitted the manuscript AAM, JPZ, AMS and FBR contributed to the study design, data analysis and manuscript writing and editing. All the authors read and approved the final manuscript.

\section{Acknowledgements}

We wish to acknowledge all those who provided support in the preparation of this manuscript. We are thankful to the Muhimbili authorities for their permission to conduct this study. We give special thanks to all nurses for their support and cooperation during data collection.

\section{Conflicts of Interest}

The authors declare no conflicts of interest regarding the publication of this paper.

\section{References}

[1] Gosain, A., Dipietro, M.D.L.A. and Ph, D. (2004) Aging and Wound Healing. World Journal of Surgery, 28, 321-326. https://doi.org/10.1007/s00268-003-7397-6

[2] Petherick, E.S., Dalton, J.E., Moore, P.J. and Cullum, N. (2006) Methods for Identifying Surgical Wound Infection after Discharge from Hospital: A Systematic Review. BMC Infectious Diseases, 6, 170. https://doi.org/10.1186/1471-2334-6-170

[3] Raykha, C., Sameh, A., Botros, R., Roden, Y. and Murchan, P. (2018) Negative Pressure Wound Therapy with Instillation as Conservative Management for a Large Abdominal Wound Following Incarcerated Parastomal Hernia Repair. Cureus, 10, e3728. https://doi.org/10.7759/cureus.3728

[4] Cher, Y.L., et al. (2014) Wound Dressings: A Primer for the Family Physician. The Singapore Family Physician, 40, 17-26.

[5] Ahmed, M., Alam, S.N., Khan, O. and Manzar, S. (2007) Post-Operative Wound Infection: A Surgeon's Dilemma. Pakistan Journal of Surgery, 23, 41-47.

[6] Nasser, A.M.A., et al. (2013) Assessment of Surgical Site Infections from Signs \& Symptoms of the Wound and Associated Factors in Public Hospitals of Hodeidah City, Yemen. International Journal of Applied Science and Technology, 3, 101-110.

[7] Woo, K., Keast, D.H., Delorme, L., Mckeough, E. and Fournier, C. (2015) Wound Care-Understanding. 1-26.

[8] Gove, J., Hampton, S., Smith, G., Hedger, C. and Topley, B. (2014) Using the Exudate Decision Algorithm to Evaluate Wound Dressings. British Journal of Nursing, 23, S24, S26-S29. https://doi.org/10.12968/bjon.2014.23.Sup6.S24

[9] Dowsett, C., Nyløkke, M. and Harding, K. (2015) Clinical Practice: Taking Wound 
Assessment beyond the Edge. Wounds International, 6, 19-23.

[10] Nixon, M. (2013) Standardising Wound Care Documentation in Clinical Practice: The Wound Healing Assessment and Monitoring (WHAM) Tool. Wounds UK, 9 , 62-66.

[11] Naude, L. (2010) The Practice and Science of Wound Healing: History and Physiology of Wound Healing. Professional Nursing Today, 14, 17-21.

[12] Fletcher, J. (2013) The Use of Electronic Data Capture Devices in Wound Care Settings. Wounds UK, 8, 119-124.

[13] Snyder, R.J., Fife, C. and Moore, Z. (2016) Components and Quality Measures of DIME (Devitalized Tissue, Infection/Inflammation, Moisture Balance, and Edge Preparation) in Wound Care. Advances in Skin \& Wound Care, 29, 205-215. https://doi.org/10.1097/01.ASW.0000482354.01988.b4

[14] Willis-Owen, C.A., Konyves, A. and Martin, D.K. (2010) Factors Affecting the Incidence of Infection in Hip and Knee Replacement: An Analysis of 5277 Cases. The Journal of Bone and Joint Surgery, 92, 1128-1133. https://doi.org/10.1302/0301-620X.92B8.24333

[15] Martone, W.J. and Nichols, R.N. (2003) Recognition, Prevention, Surveillance, and Management of SSI. Clinical Infectious Diseases, 33, 67-68. https://doi.org/10.1086/321859

[16] Jones, V., Grey, J.E. and Harding, K.G. (2006) ABC of Wound Healing; Wound Dressings. BMJ, 332, 777-780. https://doi.org/10.1136/bmj.332.7544.777

[17] Lilani, S.P., Jangale, N., Chowdhary, A. and Daver, G.B. (2005) Surgical Site Infection in Clean and Clean-Contaminated Cases. Indian Journal of Medical Microbiology, 23, 249-252.

[18] Fletcher, J. (2010) Development of a New Wound Assessment Form. Wounds UK, 6, 92-99.

[19] Ousey, K. and Cook, L. (2011) Understanding the Importance of Holistic Wound Assessment. Practice Nursing, 22, 308-314. https://doi.org/10.12968/pnur.2011.22.6.308

[20] Sibbald, R.G. and Med, M.F. (2012) Special Considerations in Wound Bed Preparation 2011: An Update. Wound Care Canada, 10, 20-35.

[21] Robert, N., Sorrell, J., Bielby, A. and Searle, R. (2011) A Survey of Postoperative Wound Dressing Practice before and after Implementing National Guidelines. Clinical Research Wound UK, 7, 12-22.

[22] Godara, R., et al. (2015) Clinical Evaluation of Effect of Early Exposure of Wounds after Minor Surgical. International Journal of Surgery and Medicine, 1, 67-71. https://doi.org/10.5455/ijsm.20150809040828

[23] Guest, J.F., Vowden, K. and Vowden, P. (2017) The Health Economic Burden That Acute and Chronic Wounds Impose on an Average Clinical Commissioning Group/Health Board in the UK. Journal of Wound Care, 26, 292-303. https://doi.org/10.12968/jowc.2017.26.6.292

[24] Greatrex-White, S. and Moxey, H. (2013) Wound Assessment Tools and Nurses' Needs: An Evaluation Study. International Wound Journal, 12, 293-301. https://doi.org/10.1111/iwj.12100

[25] Bacteria, A., Iqbal, I., Afzal, A. and Qazi, S.M. (2014) Postoperative Wounds and their Antimicrobial Sensitivity Pattern (Hospital-Based Surveillance of Aerobic Bacteria). Indian Journal of Clinical Practice, 24, 884-888.

[26] Rodriguez, P.G., Felix, F.N., Woodley, D.T. and Shim, E.K. (2008) The Role of 
Oxygen in Wound Healing: A Review of the Literature. Dermatologic Surgery, 34, 1159-1169. https://doi.org/10.1097/00042728-200809000-00001

[27] National Institute for Health and Clinical Excellence (2008) NICE Clinical Guidelines 74: Prevention and Treatment of Surgical Site Infection. London Pakistan Journal of Surgery, 23, 41-47.

[28] Erikison, H.M., Chugulu, S., Kondo, S. and Lingaas, E. (2003) Surgical Site Infection at Kilimanjaro Christian Medical Centre. The Journal of Hospital Infection, 55, 14-20. https://doi.org/10.1016/S0195-6701(03)00225-1

[29] Cheng, H., Chen, B.P., Soleas, I.M., Ferko, N.C., Cameron, C.G. and Hinoul, P. (2017) Prolonged Operative Duration Increases Risk of Surgical Site Infections: A Systematic Review. Surgical Infections, 18, 722-735. https://doi.org/10.1089/sur.2017.089

[30] Cosker, T., Elsayed, S., Gupta, S., Mendonca, A.D. and Tayton, K.J.J. (2005) Choice of Dressing Has a Major Impact on Blistering and Healing Outcomes in Orthopaedic Patients. Journal of Wound Care, 14, 27-29. https://doi.org/10.12968/jowc.2005.14.1.26722

[31] Mukagendaneza, M.J., et al. (2019) Incidence, Root Causes, and Outcomes of Surgical Site Infections in a Tertiary Care Hospital in Rwanda: A Prospective Observational Cohort Study. Patient Safety in Surgery, 13, 10. https://doi.org/10.1186/s13037-019-0190-8

[32] Lecturer, S. (2013) Understanding Effective Management of Postoperative Wounds. Wounds UK, 9, 92-95.

[33] Ding, S., Lin, F. and Gillespie, B.M. (2016) Surgical Wound Assessment and Documentation of Nurses: An Integrative Review. Journal of Wound Care, 25, 232-240.

\section{List of Abbreviations}

UK: United Kingdom

ATP: Adenosine Triphosphate

HCAIs: Health Care Associated Infections

MNH: Muhimbili National Hospital

NICE: National Institute of Health and Clinical Excellence

PACU: Postoperative Anesthesia Care Unit

SPSS: Statistical Package for Social Sciences

SSIs: Surgical Site Infections

SCU: Surgical Care Unit

MUHAS Muhimbili University of Health and Allied Sciences 


\section{Appendix 1}

\section{STANDARD NURSING PRACTICE ON WOUND CARE CHECKLIST}

Form No

\section{SECTION ONE: DEMOGRAPHIC INFORMATION}
1) Age of respondent
a) $15-24$
b) $25-34$
c) $35-44$
d) $45-54$
2) Sex
a) Male
b) Female

\section{STANDARD NURSING PRACTICE ON WOUND CARE} QUALIFICATION
3) Education
a) Secondary (o-lever)
b) Secondary (A-lever)
c) College
d) University
4) Highest level of nursing education
a) Certificate
b) Diploma
c) Degree
5) Job title (please mark only one)
d) Registered nurse
e) Enrolled nurse

NURSING PRACTICE ON POST OPERATIVE WOUND CARE

SECTION TWO

\begin{tabular}{|c|c|c|c|c|}
\hline \multirow{2}{*}{$\mathrm{SN}$} & \multirow{2}{*}{ CHARACTERISTICS TO BE OBSERVED } & \multicolumn{3}{|c|}{ PERFOMANCE } \\
\hline & & YES & NO & $\mathrm{N} / \mathrm{A}$ \\
\hline 1 & Discussion with a patient about the procedure & & & \\
\hline 2 & Ensure cleanliness and safety of environment & & & \\
\hline 3 & Ensure privacy & & & \\
\hline 4 & Wash hands before and after procedure & & & \\
\hline 5 & Assemble all needed supplies & & & \\
\hline 6 & Place waste bag for soiled items within reach & & & \\
\hline 7 & Close room or cubicles curtain or screen around & & & \\
\hline
\end{tabular}




\section{Continued}

8

1
Assist client/patient assume confortable position

Put on disposable gloves and open wound

Removing old dressing leaving inner dressing,

Use forceps; lift inner dressing off slowly

If dressing stick on the wound sock with normal saline

Observe nature of wound

Dispose of inner dressing and put them in the waste bag

Removal of disposable gloves

Arrange dressing forceps; scissors and receiver in order of their application using forceps

Pour antiseptic solution into sterile receiver

Put on sterile gloves

Inspect the wound and clean it

Using forceps and gauze dip into antiseptic solution

For each stroke of cleaning use single gauze in one direction only to avoid maximally wound contamination.

Clean from least contaminated to most contaminated area

Use fresh gauze to dry the wound

Apply dressing solution as prescribed

Apply dry sterile dressing

Use tape or adhesive plaster or bandage

Clean all used equipment and supplies

Document wound changes and client's response

\section{Communicate aspects}

Report patients level of comfort

Record data and time of dressing

Observe and record any changes in the wound

\section{Teaching aspect}

Instruct the patient/relative to avoid tempering with the wound

Instruct the patient and family to report any deviations from normal on the wound

Discuss with the patient and significant others on nutritional 


\section{ASSESSMENT OF AVAILABLE DRESSING MATERIALS}

\section{SECTION THREE}

\begin{tabular}{|c|c|c|c|}
\hline & TYPES OF DRESSING MATERIALS & YES & NO \\
\hline 1 & Trolley & & \\
\hline 2 & Toothed dissecting forceps & & \\
\hline 3 & Non toothed dissecting forceps & & \\
\hline 4 & Cheatle's forceps & & \\
\hline 5 & Jar cheatle & & \\
\hline 3 & Drum & & \\
\hline 4 & Gauze & & \\
\hline 5 & Cotton swabs & & \\
\hline 6 & Dressing towel & & \\
\hline 7 & Dressing mackintosh & & \\
\hline 8 & 2 , gall pots & & \\
\hline 9 & 2 kidney dishes & & \\
\hline 10 & 1, Artery forceps & & \\
\hline 11 & Mask & & \\
\hline 12 & Plastic Apron & & \\
\hline 13 & Sterile gloves & & \\
\hline 14 & Clean gloves & & \\
\hline 15 & Normal saline & & \\
\hline 16 & Spirit & & \\
\hline 17 & Eusol solution & & \\
\hline 18 & Hydrogen peroxide & & \\
\hline 19 & Povidone/ iodine & & \\
\hline 20 & Container for soiled items & & \\
\hline 21 & Plaster & & \\
\hline 22 & Bandages & & \\
\hline
\end{tabular}

ASSESSMENT ON PROPER USE OF THE AVAILABLE DRESSING

MATERIALS

SECTION FOUR

\begin{tabular}{|c|c|c|c|}
\hline \multirow{2}{*}{ SN } & \multirow{2}{*}{ DRESSING MATERIALS } & \multicolumn{2}{|c|}{ PERFORMANCE } \\
\hline & & YES & NO \\
\hline 1 & Dust dressing Trolley for carrying equipment & & \\
\hline 2 & Place bag for soiled item within patient reach & & \\
\hline 3 & Put on disposable (clean) gloves when opening wound & & \\
\hline 4 & Using toothed dissecting forceps to lift inner dressing off slowly & & \\
\hline
\end{tabular}




\section{Continued}

5 Use normal saline to sock the wound if dressing sticks on the wound

6 Pour antiseptic solution into sterile receiver (kidney dish or gall pots)

$7 \quad$ Put on sterile gloves while dressing the wound (Use one glove for one patient)

8 Clean the wound by using forceps (non toothed dissecting forceps)

9 Use single sterile gauze in one direction only

10 Use fresh gauze to dry the wound

11 Apply dressing solution as prescribed

12 Apply dry sterile dressing

13 Use tape or adhesive plaster to secure dressing 